\title{
Research
}

\section{Network analysis by simulated annealing of taxa and islands of Macaronesia (North Atlantic Ocean)}

\author{
Giancarlo Torre, Silvia Fernández-Lugo, Riccardo Guarino and José María Fernández-Palacios
}

G. Torre (http://orcid.org/0000-0001-7708-5223) (giancarlotorre@hotmail.it) and R. Guarino (http://orcid.org/0000-0003-0106-9416), Dept STEBICEF - Botanical Unit, Palermo Univ., Italy. - S. Fernández-Lugo and J. M. Fernández-Palacios (http://orcid.org/0000-0001-9741-6878), Island Ecology and Biogeography Research Group, Inst. Universitario de Enfermedades Tropicales y Salud Pública de Canarias (IUETSPC), Univ. de La Laguna, Tenerife, Canary Islands, Spain.

\section{Ecography}

42: 1-12, 2018

doi: 10.1111/ecog.03909

Subject Editor: Michael Borregaard Editor-in-Chief: Miguel Araújo Accepted 4 October 2018
With the aim of explaining the role that taxa and island features have in biogeographical patterns, we processed presence-absence matrices of all the Macaronesian native species of ten different taxa (arthropods, birds, bryophytes, fungi, lichens, mammals, mollusks, pteridophytes, reptiles and spermatophytes) through simulated annealing analysis. Distribution patterns among the archipelagos were pinpointed, along with the different biogeographic roles played by islands and species groups. All the networks analysed resulted to be significantly modular and the structure of biogeographic modules reflects known past connections among the archipelagos and the current drivers of species distribution. The role assigned to the species supports some biological (ecological amplitude, degree of endemicity) and functional (long-distance dispersal and persistence abilities) traits of their respective biota and justifies their position in recent models of biogeographical distribution. Whereas it was expected that the modules identified by the spermatophytes and arthropods would reflect the compartmentalization of archipelagos quite well, this was also the case for much more vagile taxa, such as fungi or lichens. Conversely, results obtained for pteridophytes and bryophytes suggest that for those taxa geographic distance and/or macroclimatic conditions are less important than the size, age and orography of an island to determine the modularity of island groups. On the other hand, dry, species-poor islets, act as connectors, tending to cluster together for different taxa, independently of their archipelagic adscription, whereas large, high, humid islands tend to form network or module hubs representing regional centers of speciation and dispersal.

Keywords: Macaronesia, insular networks, island biogeography

\section{Introduction}

Oceanic islands are popular targets to test specific evolutionary or ecological hypotheses. Following the publication of the Theory of island biogeography (MacArthur and Wilson 1967) a wide array of different models and approaches have been proposed to explain species richness and distribution patterns on islands (Fattorini 2009, 2011,

(C) 2018 The Authors. Ecography (C) 2018 Nordic Society Oikos 
Warren et al. 2015, Whittaker et al. 2017). Species richness on islands depends on a dynamic equilibrium between immigration and extinction, along with on-site speciation, which are influenced by the duration of isolation, distance from the mainland, size of the island, as well as geomorphologic diversity and sea-level fluctuations (Heaney 2000, Lomolino 2000, Whittaker et al. 2008, Fattorini 2010, FernándezPalacios et al. 2016).

Species presence-absence records provide a useful means for assembling current species distribution patterns and for interpreting ecological patterns related to alpha and beta diversity (Fattorini 2010, Podani and Schmera 2011). Additionally, the identification and delimitation of biogeographic modules (i.e. taxa distribution ranges with comparable features, supporting similar biota) through the analysis of species and geographic typological units allow defining the most probable source/sink and metapopulational dynamics for among- and within-archipelago species dispersal (dos Santos et al. 2008).

Traditional approaches in biogeographic pattern analysis often imply an arbitrary delimitation of boundaries. Network analysis is a promising tool for understanding biogeographic connectivity and evaluating patterns and interactions within complex networks, because it offers an approach free from a priori hypotheses on data sets (Olesen et al. 2007). It also combines information on the size and consistency of distribution ranges, allowing a more detailed and accurate geographic partitioning than a traditional cluster analysis (Carstensen and Olesen 2009).

An algorithm for modularity detection through species distribution analysis was developed by Guimerà and Amaral (2005a) and has been used to identify biogeographic modules and topological roles (i.e. roles in continuity and connectedness) of islands and species in Central Aegean archipelago (Kougioumoutzis et al. 2014), Wallacea (Carstensen and Olesen 2009) and West Indies (Carstensen et al. 2012, 2013). The same method has additionally been used to analyze metabolic networks (Guimerà and Amaral 2005b), pollination networks (Olesen et al. 2007) and to delineate networks of invasive species on the Galápagos islands (Traveset et al. 2013).

Macaronesia (Fig. 1 and Table 1) is a biogeographical region encompassing five archipelagos of the NE Atlantic Ocean, in decreasing order of latitude: the Azores, Madeira, Salvages, the Canaries and Cape Verde. All these archipelagos share a common volcanic origin and an oceanic location, although they display important differences such as their climate, varying from mild and wet under the influence of the Gulf stream in the Azores $\left(38-40^{\circ} \mathrm{N}\right)$, to a Mediterranean type climate in Madeira and the Canaries to a very dry, summerrain monsoon climate in Cape Verde (de Nicolás et al. 1989). Additionally, whereas Azores, the Canaries and Cape Verde archipelagos have been affected by historic volcanism, the last eruption in Madeira happened $7 \mathrm{Ky}$ ago (Geldmacher et al. 2000).

With a total surface area of approximately $15000 \mathrm{~km}^{2}$ Macaronesia includes 40 islands $>1 \mathrm{~km}^{2}$ stretching from $14.8^{\circ} \mathrm{N}$ (Brava, Cape Verde) to $39.7^{\circ} \mathrm{N}$ (Corvo, Azores) and

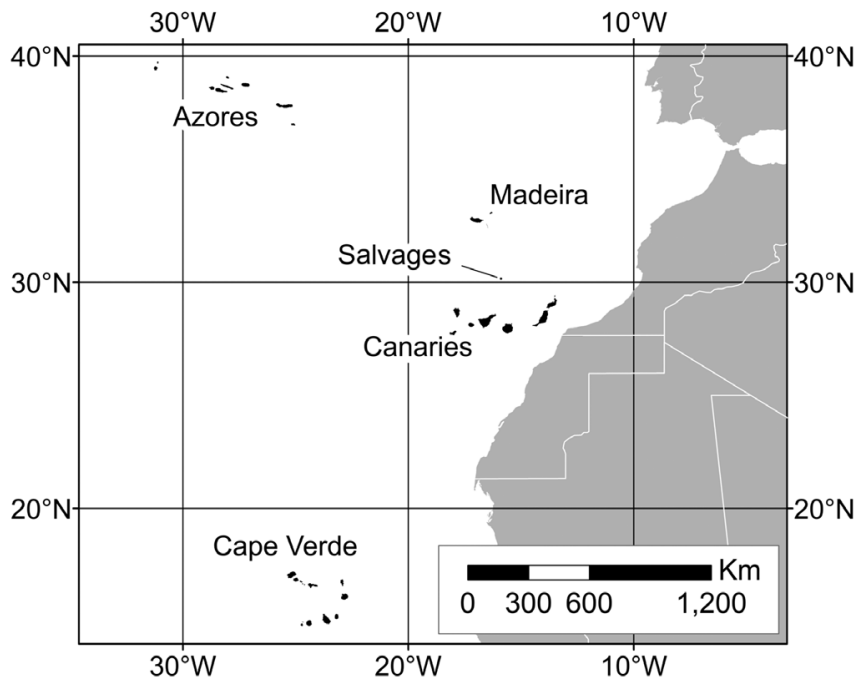

Figure 1. Geographic position of the archipelagos and islands of Macaronesia.

from $13.4^{\circ} \mathrm{W}$ (Roque del Este, Canaries) to $30.9^{\circ} \mathrm{W}$ (Flores, Azores). Each archipelago is made up of de novo oceanic volcanic islands that emerged in relatively recent times (27-0.25 $\mathrm{Myr}$ ) and were never connected to the mainland (FernándezPalacios et al. 2011). Given Macaronesia represents a group of islands with the same formation history, and accumulation of species has thus only occurred by long-distance dispersal events and in situ diversification, the system offers a uniform backdrop to evaluate concurrent patterns of island biogeography in overlapping taxa.

The biogeographic entity of Macaronesia as a region was postulated for the first time by Engler (1879) and substantially accepted until today but, even if the affinity between Canary Islands and Madeira is widely recognized, the zoogeographic and phytogeographic uniformity of the whole Macaronesian region is a controversial issue (Kunkel 1980, Lobin 1982, Beyhl et al. 1995, Lüpnitz 1995, Santos-Guerra 1999, Vanderpoorten et al. 2007). The only clear assumption is that all these archipelagos display various connections among themselves and with different continental regions.

Recent developments in the understanding of the geological and environmental evolution of the Macaronesian islands, including an increasing number of phylogenetic studies on the Macaronesian lineages (Caujapé-Castells 2011, Price et al. 2018) and many fossil findings (de Nascimento et al. 2009, Martín González 2009) provide new interesting scenarios in the history of the biological colonization of these islands, supporting and integrating alternative biogeographic models and hypotheses. The biogeography of the Macaronesian region is influenced by three main abiotic processes: 1) islands' emersion in different temporal stages (Fernández-Palacios et al. 2011); 2) existence of shifting winds and marine current regimes favoring the arrival of propagules from the Mediterranean and Maghreb regions (although there are some important exceptions) (FernándezPalacios et al. 2013); and 3) repeated Pleistocene sea level 
Table 1. Archipelagos and islands included in the analysis, with their abbreviation and relevant geographical data. In the last column, the bibliographic source of the checklists is reported.

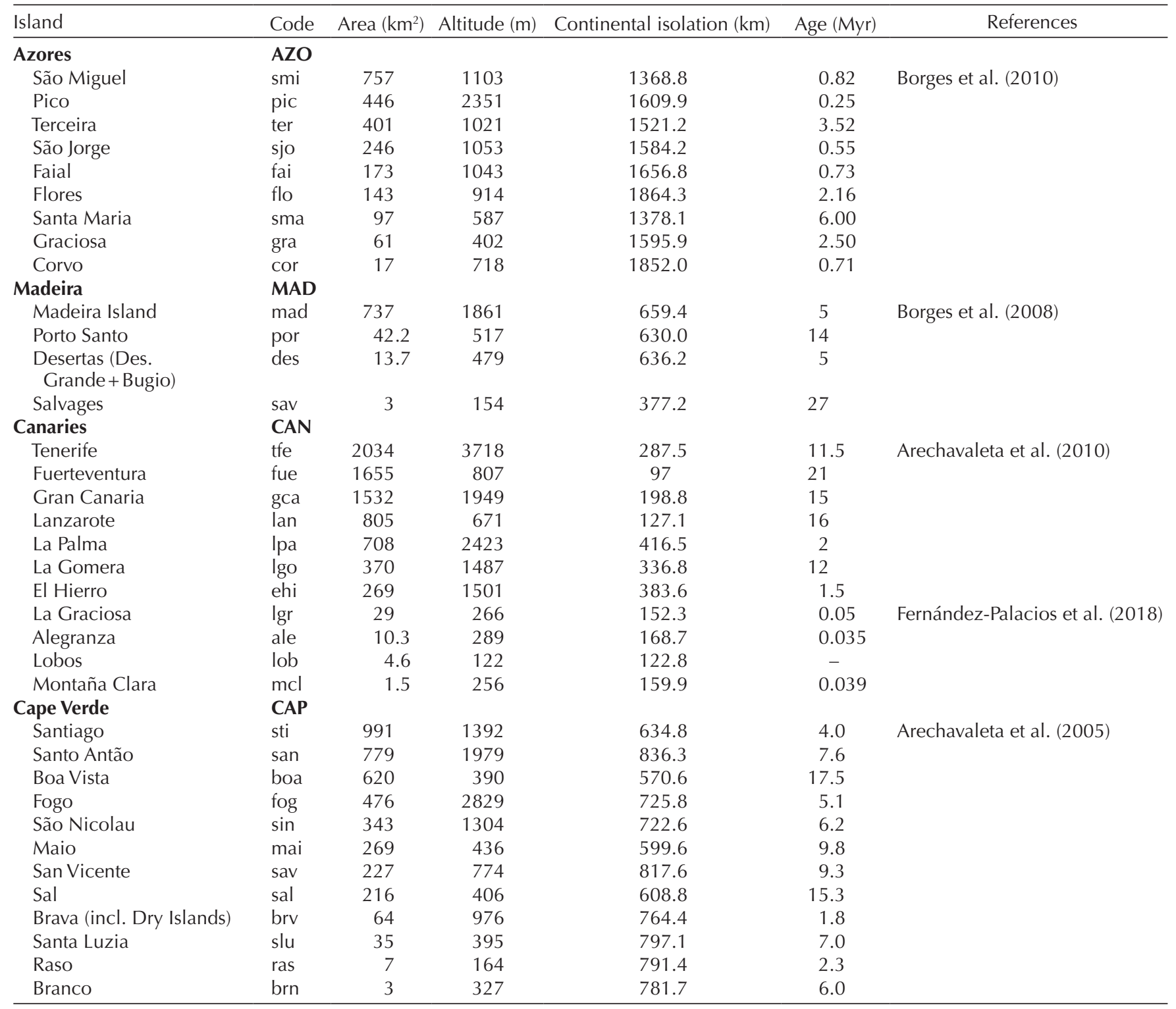

fluctuations, which favored the emergence of stepping stones facilitating the species flow towards and within the archipelagos (Rijsdijk et al. 2014).

In relation to the nature of Macaronesian biogeographic modules and topological roles we postulate two different, complementary hypotheses: 1) the biogeographical units obtained within Macaronesia will mainly depend on the taxonomic group studied, so that taxa with different vagility, persistence ability or ecological amplitude will produce different, contradictory biogeographical patterns. This is to say that we expected that for some taxa archipelagic entities will prevail, whereas for others, archipelagic entities will be diluted in other, more bizarre, island clusters that combine geographically and ecologically similar islands of different archipelagos; 2) islands with similar geographic and environmental conditions, will display a similar local or regional topological role, independently of their archipelagic adscription. In order to test these hypotheses, we applied the network analysis method to both Macaronesian biota and islands to: 1) quantify the occurrence and intensity of biotic relationships among the Macaronesian archipelagos checking whether the current biogeographic units are statistically supported by the presence of native species in the main terrestrial Macaronesian taxa; 2) identify biogeographic clusters of islands and taxa, comparing their modularity; 3) provide a useful tool for correlating the biogeographic roles assigned by network analysis to species and islands having common traits and features; 4) understand whether and how these correlations vary, depending on taxa analysed. 


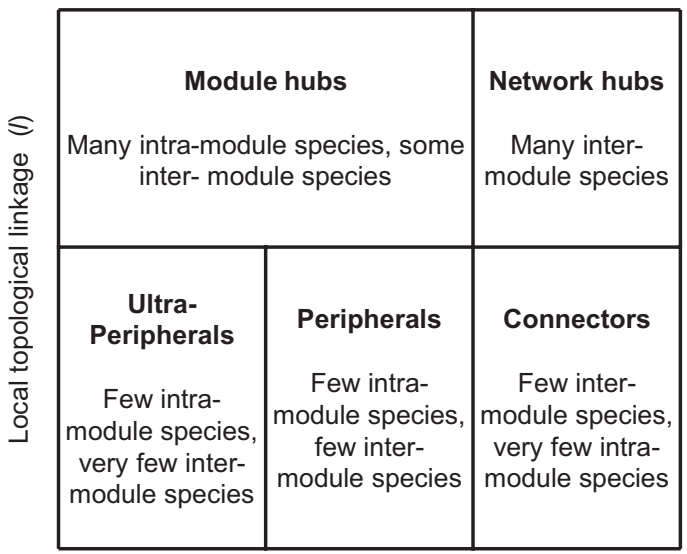

Regional topological linkage $(r)$

Figure 2. Conceptual framework of the biogeographic roles of islands in the $r$ - $l$ space. The size and position of the areas associated to each role reflect the average partitioning in the diagrams reported in Supplementary material Appendix 3.

\section{Methods}

\section{Data bases}

Our analysis is based on native species presence-absence data available for 36 Macaronesian islands $>1 \mathrm{~km}^{2}$. The processed data were taken from the most recent checklists existing for the Macaronesian biota (Table 1). We arranged the collected presence-absence data into 10 matrices, corresponding to the following groups of terrestrial organisms, hereafter referred to as 'Taxonomic Operational Units' (TOUs): arthropods, birds, bryophytes, fungi, lichens, mammals, mollusks, pteridophytes, reptiles and spermatophytes. Only the TOUs with records available from all insular units have been considered. Some phyla were excluded from our

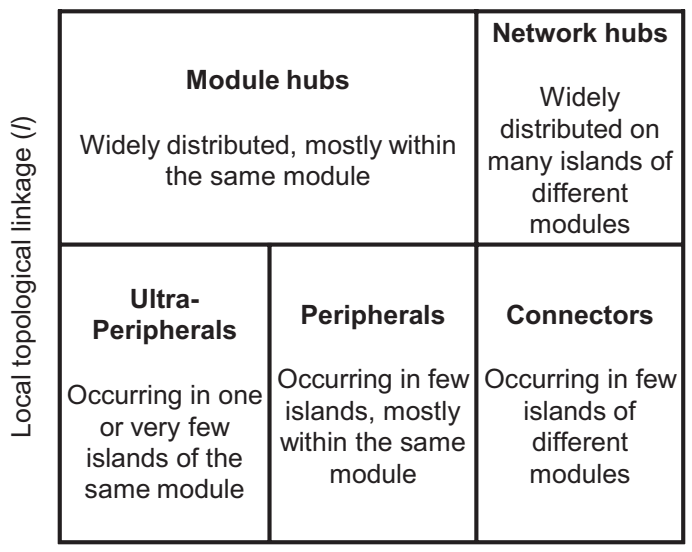

Regional topological linkage $(r)$

Figure 3. Conceptual framework of the biogeographic roles of species in the $r$-l space. The size and position of the areas associated to each role reflect the average partitioning in the diagrams reported in Supplementary material Appendix 3. analyses because of data deficiency (such as bacteria, collembolan, helminths, protozoa, etc.), while others (such as amphibians and freshwater fishes) were excluded because of the lack of native species. Finally, we left out marine organisms due to data incompleteness and problems of assigning them to specific islands.

Each matrix consisted of 36 columns $\times n$ rows, with $n$ given by the complete list of the recorded native terrestrial species for each TOU in all the 36 insular units considered. All processed matrices are available on-line (Supplementary material Appendix 1).

In an effort to minimize the interference of human impacts, our analyses are based only on native species. Doubtful records have been discarded, but not the species reported as extinct in recent times on a given island. Due to the high number of subspecies designating the populations of each single island, especially in the field of vascular plants and reptiles, it was decided to lump all infra-specific taxa with the nominal species, so to emphasize the insular connections among closely related lineages.

Nomenclature and synonymies were standardized according to Arechavaleta et al. (2010) and, for the species not occurring in the Canary Islands, standardization was based on the most recent available repertories, such as the Plant List (<www.theplantlist.org> accessed October 2017) for vascular plants and bryophytes.

\section{Data processing}

The network analysis followed the approach developed by Guimerà and Amaral (2005a, b) and by Olesen et al. (2007). We used simulated annealing, included in the NETCARTO software package (Guimerà and Amaral 2005a, b), in order to define the modular structure of networks and assign a role to each node (species and islands), based on the number and pattern of its links (Supplementary material Appendix 2). Scatterplots displaying the topological role of species and islands were obtained through the IBM SPSS statistics package (Supplementary material Appendix 3).

\section{Modularity}

Modularity is determined by species and island traits, accounting for non-random distributional patterns and community ties, which contribute to the complexity of ecological networks (Trøjelsgaard et al. 2013). According to Guimerà et al. (2004), in a modular network, clusters of strongly connected nodes form a module, while the modules are linked together by minimizing the number of inter-modular links and the intra-modular number of nodes, for obtaining the most articulated possible network.

Modules are identified by maximizing the network modularity through the simulated annealing approach. The advantage of this procedure is that it is not necessary to specify the number of modules a priori, because this number derives directly from the application of an algorithm which identifies modules in a network of nodes those that 
allow retainment of at least $50 \%$ of the links within of the module itself.

Modularity $(\mathrm{M})$ is defined by the formula:

$$
M \equiv \sum_{s=1}^{N_{M}}\left[\frac{l_{s}}{L}-\left(\frac{d_{s}}{2 \mathrm{~L}}\right)^{2}\right]
$$

Where $N_{M}$ is the number of modules; $L$ is the number of links in the network; $l$ is the number of links between the notes of the module; and $d_{s}$ is the sum of the degrees of nodes in the module $s$. The simulated annealing is an iterative stochastic optimization technique that allows the most advantageous configuration by introducing a computational temperature; at each time step, the algorithm randomly selects a configuration (solution) close to the current one, measures its quality, and then decides to move to it if the new solution is better than that of the previous step. During the search, the computational temperature was progressively decreased from an initial positive value (network size/2) to zero and at each step of the procedure, the temperature was decreased to a new temperature, $\mathrm{T}^{\prime}=c \mathrm{~T}$, where $c$ is the cooling factor. We applied $c$ at a value of 0.95 , as suggested by Guimerà et al. (2007) for large networks.

In the current study, modules are the formation of clusters of species and islands, which are closely linked to each other. Thus, each module represents the core area of a group of species. The modularity index $\mathrm{M}$ was evaluated for each possible configuration of the network: the more $\mathrm{M}$ approaches 1 , the more modules are defined and distinct; the more it approaches 0 , the smaller the difference between modules. To test the significance of modularity, the empirical values of $\mathrm{M}$ were compared with that of 100 randomized network configurations having the same number of links and nodes of the empirical one. The modularity of the empirical network was considered significant if its $M$ value was higher than that of $95 \%$ of randomized networks.

\section{Topological role}

After finding the best network configuration, the topological role of each species and island in the network was evaluated using the following parameters.

1) Standardized within-module degree $(l)$, given by:

$l_{i}=\frac{k_{i s}-\bar{k}_{s}}{S D_{k s}}$

2) Inter-module connectivity $(r)$, given by the formula:

$$
r_{i}=1-\sum_{t=1}^{N_{M}}\left(\frac{k_{i t}}{k_{i}}\right)^{2}
$$

in which $k_{i}$ is the number of links of the node $i ; k_{i s}$ is the number of links of $i$ to the other nodes of the same module $s ; \bar{k}$ and $S D_{k s}$ are mean and standard deviation of $k$ values within the module $s$; and $k_{i t}$ is the number of links from $i$ to the other nodes of the module $t$.
The standardized within-module degree $(l)$, or local topological linkage, evaluates how much a node $i$ is connected to its module in relation to the other nodes of the module; whereas the inter-module connectivity $(r)$, or regional topological linkage, evaluates how much a node $i$ is connected to the other modules (Guimerà and Amaral 2005b, Olesen et al. 2007, Carstensen et al. 2012).

Therefore, the species richness of a given island and the number of occurrences of each species in the other islands of the considered region determine the positions of the island and the species in the two-dimensional $l-r$ space.

For classification of the topological roles into a biogeographic framework, we followed the method outlined by Guimerà and Amaral (2005a) that was modified by Olesen et al. (2007), but we recognize one more role (ultraperipherals, a term first coined by Guimerà and Amaral 2005 b), in order to provide a clearer separation between single-island endemics (SIEs) and species occurring on multiple islands of the same module. The numerical thresholds of $l$ and $r$ for the assignment to biogeographic roles are given in Table 2. A short definition of the topological roles assigned to islands and species is reported in Fig. 2 and Fig. 3, respectively.

\section{Data deposition}

Data available from the Dryad Digital Repository: < https:// doi.org/10.5061/dryad.v190524> (Torre et al. 2018).

\section{Results}

The obtained database consisted of 17697 species and 55819 occurrences distributed in 36 insular units. The scores of the considered TOUs per insular unit are presented (Table 3 ) and the relative occurrences of TOUs per archipelago are shown in Fig. 4.

The outputs of the network analyses for each of the species and insular units processed can be accessed on-line (Supplementary material Appendix 2 and 3), along with the module assigned, the number of links in each module and the $r$ and $l$ values defining the topological role of each module. The modules resulting from the network analyses are shown in Table 3-5 and in Fig. 5-6. The roles assigned to each insular unit by the TOUs considered are shown in Fig. 7.

Table 2. Threshold values of local $(I)$ and regional $(r)$ topological linkages for the assignment of biogeographic roles to islands and species. Nodes with $r \leq 0.625$, have at least $60 \%$ of their links within the same module.

\begin{tabular}{lclc}
\hline Biogeographic role & $I$ (islands) & $I$ (species) & $r$ \\
\hline Network hub & $>2.5$ & $>$ median & $>0.625$ \\
Module hub & $>2.5$ & $>$ median & $\leq 0.625$ \\
Connector & $\leq 2.5$ & $\leq$ median & $>0.625$ \\
Peripheral & $\leq 2.5$ & $\leq$ median & $0.05<r \leq 0.625$ \\
Ultra-peripheral & $\leq 2.5$ & $\leq$ median & $\leq 0.05$ \\
\hline
\end{tabular}




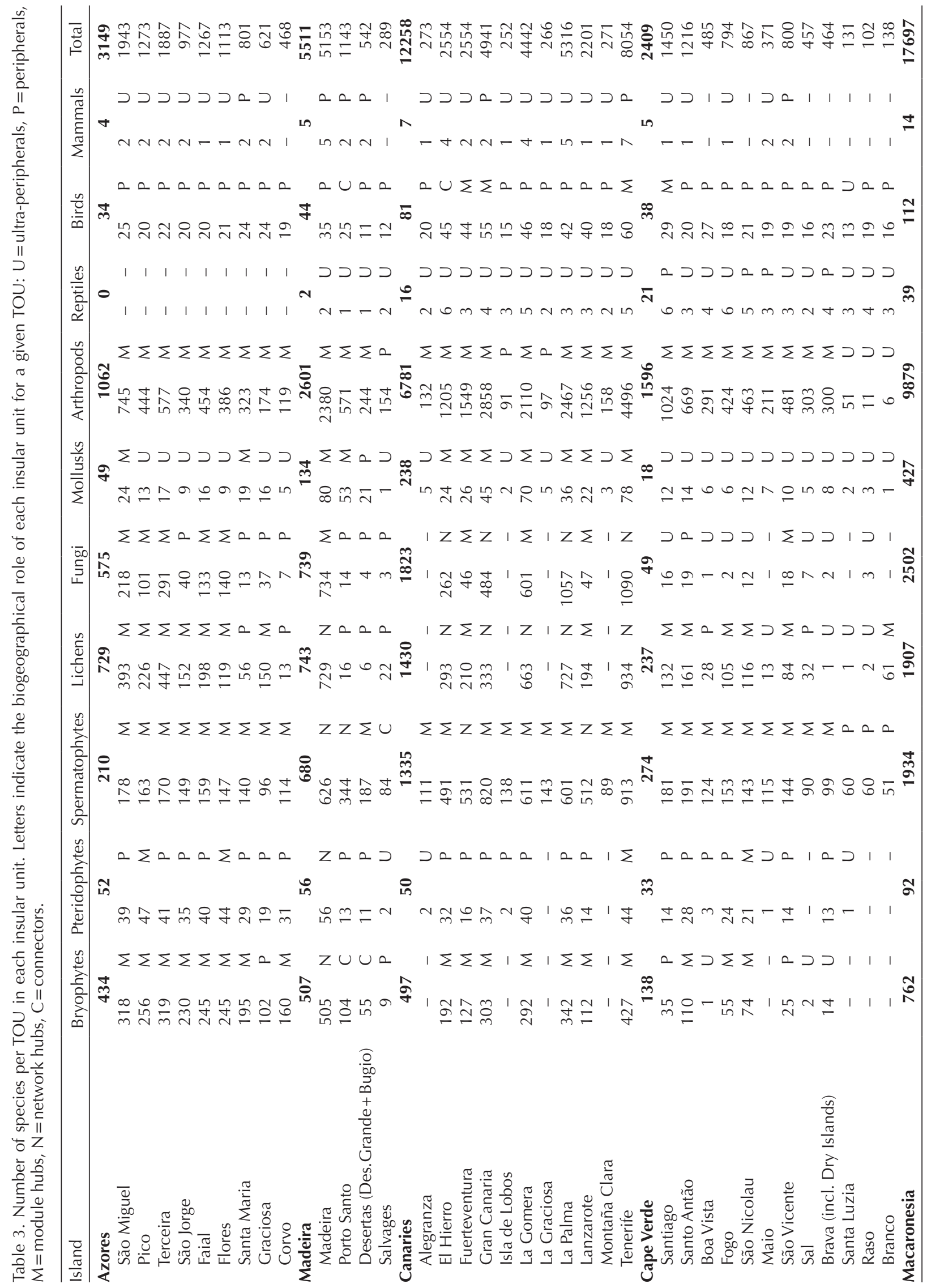




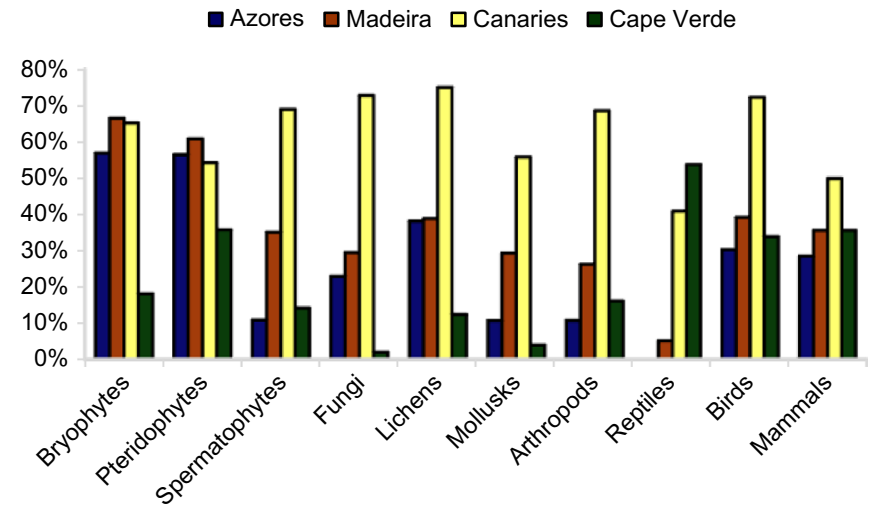

Figure 4. Percentage composition of the Macaronesian biota per TOU and archipelago.

\section{Modularity patterns observed among the different taxonomic groups}

The occurrence within bryophytes of two Madeiran insular units in the same module of Cape Verde (Table 4) is very likely due to the scarcity of species, most of which being generalists, recorded both in Porto Santo and Desertas. This is confirmed by the role of connector assigned to these two islands. In the case of pteridophytes, the separation of Lobos and Alegranza in two modules other than the Canarian archipelago (Table 4) may be due to randomness, as there are only four fern species on both islands, all of which are widely distributed throughout Macaronesia. The same applies to Santa Luzia and Maio, which have only one species, Ophioglossum polyphyllum, occurring in almost all the Canary Islands, but only occurring on four other Cape Verde islands.

The modules identified by the spermatophytes (Table 4) and arthropods (Table 5) are very similar, reflecting the compartmentalization of archipelagos quite well, with the remarkable splitting in both taxa of the western and eastern Canaries, due to their environmental differences. In the case of arthropods, the Salvages are lumped in the module of eastern Canaries, as one would expect from palaeobiogeographic evidences.

Fungi and lichens modules were expected to be determined most by geomorphologic and climatic conditions, rather than by distance between insular units. Nevertheless, both modules reflect the partitioning of archipelagos rather well, especially lichens. The low number of fungal species, all connectors, recorded in the insular units of the first module is probably due to similar geomorphologic and climatic conditions: the driest, flattest and stoniest insular units of the Canarian and Madeiran archipelagos host a fungal diversity comparable to that of the Cape Verde islands (Table 4).

Table 4. Modules identified by the vegetal TOUs: $\mathrm{n}=$ number of nodes; $\mathrm{IM}=$ intra-modular links; $\mathrm{EM}=$ extra-modular links.

\begin{tabular}{|c|c|c|c|}
\hline Modules & $\mathrm{n}$ & IM & EM \\
\hline \multicolumn{4}{|l|}{ Bryophytes $\left(M=0.28 ; M_{\text {random }}=0.17 ; p=0.002\right)$} \\
\hline AZO & 268 & 1503 & 1223 \\
\hline Mad & 128 & 127 & 496 \\
\hline $\mathrm{CAP}+$ por + des & 97 & 285 & 671 \\
\hline \multicolumn{4}{|l|}{ Pteridophytes $\left(M=0.32 ; M_{\text {random }}=0.20 ; p=0.004\right)$} \\
\hline $\mathrm{AZO}$ & 47 & 251 & 162 \\
\hline CAP (except mai and slu) + ale & 26 & 82 & 95 \\
\hline \multicolumn{4}{|l|}{ Spermatophytes $\left(M=0.48 ; M_{\text {random }}=0.23 ; p=0.002\right)$} \\
\hline AZO & 206 & 1287 & 481 \\
\hline MAD & 361 & 671 & 1118 \\
\hline $\mathrm{ehi}+\mathrm{gca}+\operatorname{lpa}+\mathrm{tfe}+\operatorname{lgo}$ & 845 & 2190 & 1850 \\
\hline$|g r+f u e+a l e+l a n+l o b+m c|$ & 290 & 860 & 1373 \\
\hline tfe & 408 & 407 & 819 \\
\hline lgo & 385 & 384 & 864 \\
\hline ehi + gca & 272 & 399 & 837 \\
\hline $\operatorname{lp} a+$ fog & 436 & 436 & 763 \\
\hline cor + sma + fue + lan + CAP (except fog) & 111 & 161 & 282 \\
\hline \multicolumn{4}{|l|}{ Lichens $\left(M=0.36 ; M_{\text {random }}=0.27 ; p=0.001\right)$} \\
\hline AZO (except cor) & 475 & 1245 & 1205 \\
\hline mad & 281 & 280 & 647 \\
\hline tfe + lpa + lgo & 701 & 1218 & 1553 \\
\hline por + gca,+ fue + lan + ehi & 299 & 527 & 1083 \\
\hline $\mathrm{CAP}+\mathrm{des}+\mathrm{sav}+\mathrm{cor}$ & 174 & 643 & 854 \\
\hline
\end{tabular}


Table 5. Modules identified by the animal TOUs: $n=$ number of nodes; IM=intra-modular links; EM=extra-modular links.

\begin{tabular}{|c|c|c|c|}
\hline Modules & $\mathrm{n}$ & IM & EM \\
\hline \multicolumn{4}{|l|}{ Mollusks $\left(M=0.77 ; M_{\text {random }}=0.56 ; p=0.005\right)$} \\
\hline AZO & 58 & 134 & 12 \\
\hline $\mathrm{mad}+\mathrm{des}$ & 78 & 90 & 15 \\
\hline por & 51 & 50 & 8 \\
\hline lgo & 57 & 56 & 17 \\
\hline$f u e+l o b+\operatorname{lgr}+\operatorname{lan}+\mathrm{mcl}+\mathrm{ale}$ & 43 & 60 & 13 \\
\hline gca & 41 & 40 & 13 \\
\hline lpa + ehi & 41 & 47 & 36 \\
\hline tfe & 62 & 61 & 18 \\
\hline CAP & 30 & 86 & 2 \\
\hline sav & 2 & 1 & 0 \\
\hline \multicolumn{4}{|l|}{ Arthropods $\left(M=0.49 ; M_{\text {random }}=0.28 ; p=0.002\right)$} \\
\hline $\mathrm{AZO}$ & 851 & 3242 & 1911 \\
\hline MAD (except sav) & 1573 & 1986 & 2240 \\
\hline fue $+\operatorname{lob}+\mathrm{mcl}+\mathrm{ale}+\lg r+\operatorname{lan}+\mathrm{sav}$ & 1191 & 2223 & 2699 \\
\hline $\mathrm{tfe}+\operatorname{lgo}+\mathrm{gca}+$ Ipa $+\mathrm{ehi}$ & 4644 & 9533 & 4734 \\
\hline CAP & 1432 & 3926 & 1486 \\
\hline \multicolumn{4}{|l|}{ Reptiles $\left(M=0.74 ; M_{\text {random }}=0.58 ; p=0.017\right)$} \\
\hline MAD & 6 & 6 & 0 \\
\hline $\mathrm{ehi}+$ gca + Ipa + lgo +tfe & 18 & 24 & 0 \\
\hline $\mathrm{ale}+\mathrm{fue}+\mathrm{lob}+\mathrm{lan}+\mathrm{mcl}+\lg r$ & 9 & 15 & 0 \\
\hline $\mathrm{brn}+\mathrm{sar}+\mathrm{slu}+\mathrm{svi}+\mathrm{san}$ & 12 & 16 & 3 \\
\hline $\mathrm{boa}+\mathrm{mai}+\mathrm{sal}+\mathrm{sti}+\mathrm{fog}+\mathrm{brv}$ & 16 & 22 & 3 \\
\hline (1) & 5 & 4 & 2 \\
\hline \multicolumn{4}{|l|}{ Birds $\left(M=0.37 ; M_{\text {random }}=0.21 ; p=0.004\right)$} \\
\hline $\mathrm{AZO}+\mathrm{MAD}$ & 46 & 204 & 180 \\
\hline CAN (except ale and mcl) & 53 & 207 & 212 \\
\hline $\mathrm{CAP}+\mathrm{ale}+\mathrm{mcl}$ & 49 & 237 & 154 \\
\hline \multicolumn{4}{|l|}{ Mammals $\left(M=0.57 ; M_{\text {random }}=0.49 ; p=0.019\right)$} \\
\hline AZO (except flo) & 9 & 12 & 1 \\
\hline flo & 2 & 1 & 0 \\
\hline fue + ale + lan $+\operatorname{lgr}+\mathrm{mcl}+\mathrm{lob}+\mathrm{gca}+\mathrm{svi}$ & 10 & 9 & 3 \\
\hline Ipa $+\operatorname{lgo}+$ tfe + ehi + mad + fog & 12 & 24 & 7 \\
\hline san & 2 & 1 & 0 \\
\hline des + por + mai + sti & 6 & 5 & 3 \\
\hline
\end{tabular}

Terrestrial mollusks is the TOU generating more distribution modules, due to the high prevalence of SIEs, especially in the Canaries, where several modules consist of one single island. Contrastingly, Azores and Cape Verde archipelagos form unique, independent modules (Table 5).

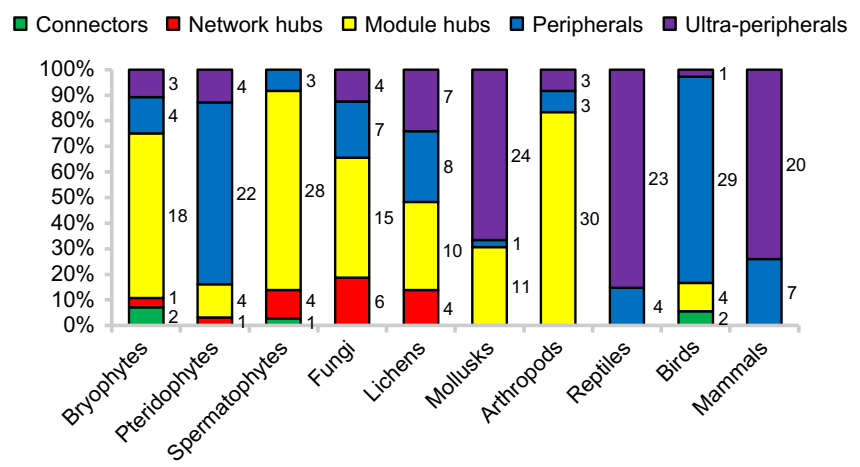

Figure 5. Role (\%) of the insular units per TOU. $\square$ Connectors $\square$ Network hubs $\square$ Module hubs $\square$ Peripherals $\square$ Ultra-peripherals

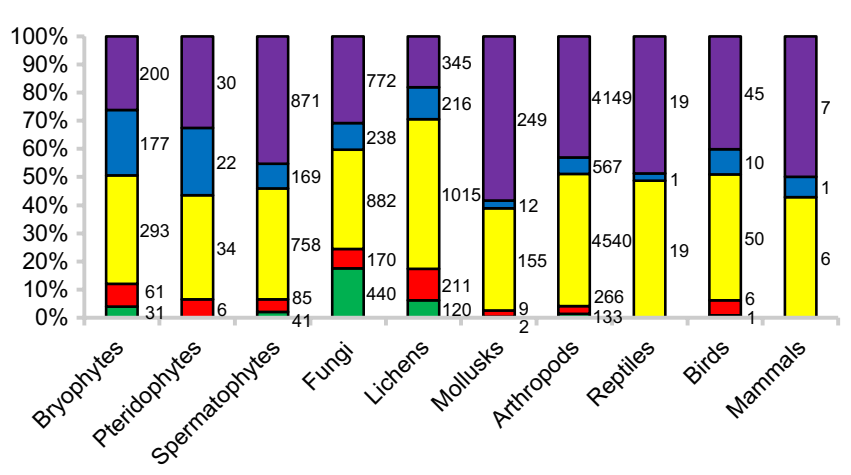

Figure 6. Role (\%) of the species per TOU.

Reptile distribution reflects the partitioning of archipelagos (n.b.: Azores have no native reptiles), with the Canaries splitting in high and low islands and Cape Verde in windward and leeward islands. The island of Sáo Nicolau, with its 5 reptile species of which 3 endemic, forms a self-contained module (Table 5).

Birds modular partitioning is the lowest in the examined TOUs, likely due to the large number of species widely distributed among the islands, particularly among sea birds (Table 5). The occurrence of Alegranza and Montaña Clara in the module of Cape Verde is very likely driven by the scantiness of bird species (20 and 18 respectively, all of which are marine), compared to the rest of the Canary Islands. Moreover, these two islands host two nesting species of pelagic birds shared with Cape Verde and not with the Canaries. Finally, the low number of mammal species (14, of which 13 are bats) and of endemics (3 species) causes a modularization not reflecting the partitioning of the Macaronesian archipelagos (Table 5). The whole region can be considered rather homogeneous regarding the occurrences of mammals. Only Santo Antão (Cape Verde) and Flores (Azores) form a self-contained module because each island possesses a single species of bat that, although not endemic, is found only there in Macaronesia.

\section{Discussion}

As expected in our initial hypotheses, modularity patterns resulted to be largely dependent on the OTUs considered, with less vagile taxa mirroring the geographic compartmentalization of archipelagos and more vagile taxa mirroring the inter-insular ecological and geomorphological similarities. As for the topological role of islands, those with similar structural and environmental conditions display a similar local or regional role, independently of their archipelagic adscription.

\section{Biogeographic patterns inferred from modularity}

The geological history and distances among the Macaronesian archipelagos is well represented by modularity patterns, for both abundant (e.g. plants and arthropods) and scarce 


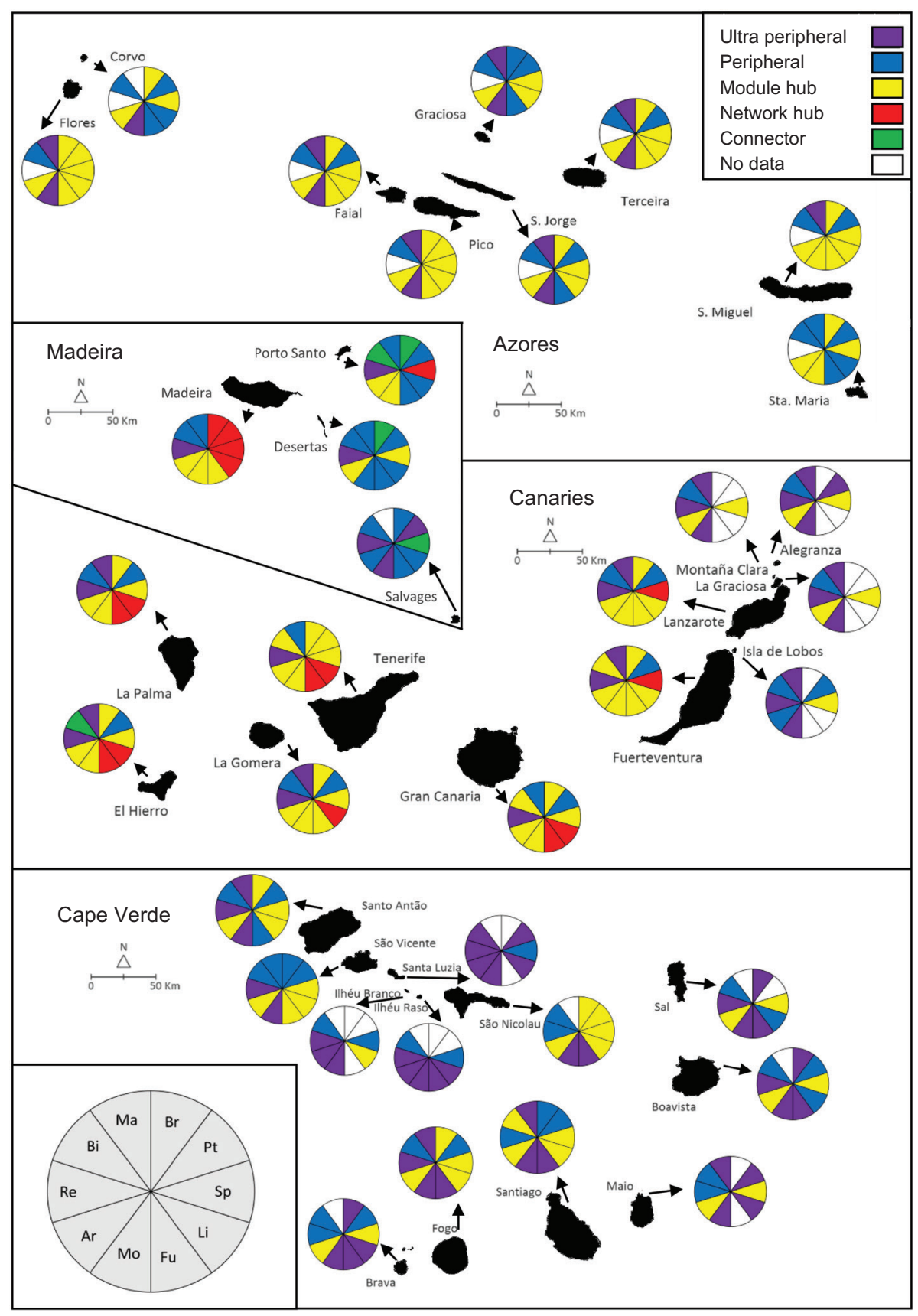

Figure 7. Biogeographic role assigned to the insular units by the topological analysis of the modularity revealed by each considered TOU. As expected, taxa with different vagility, persistence ability or ecological amplitude can produce different, sometimes incongruent biogeographical patterns (further details in the Discussion). Abbreviations: $\mathrm{Br}=$ bryophytes; $\mathrm{Pt}=$ pteridophytes; $\mathrm{Sp}=$ spermatophytes; Li $=$ lichens; $\mathrm{Fu}=$ fungi; $\mathrm{Mo}=$ mollusks; $\mathrm{Ar}=$ arthropods; $\mathrm{Re}=$ reptiles; $\mathrm{Bi}=$ birds; $\mathrm{Ma}=$ mammals.

(e.g. reptiles) groups of taxa. For other TOUs, such as bryophytes and pteridophytes, mainly characterized by their long distance dispersal ability, the modules obtained show some small discrepancies with the geographical division of the archipelagos.

The models obtained for fungi, lichens, mammals and birds, however, suggest that for these organisms geographic distances and/or macroclimatic conditions are less important than other drivers, such as microclimate, island age and size, orography or availability of trophic niches. For example, in the case of lichens, Corvo (Azores) and Cape Verde as a whole were combined within the same module, despite these islands being separated by the longest distance we can find within Macaronesia (> $2500 \mathrm{~km}$ ). In the case of fungi, all the driest islands of each archipelago were lumped together in the same module of Cape Verde (except Fogo), whereas 
geomorphologically complex islands, such as Tenerife or La Gomera, formed modules apart.

The modularity revealed by terrestrial mollusks show that while both the Azores and Cape Verde form a wellcircumscribed module respectively, Madeira and, especially, the Canary Islands were split into eight modules, likely reflecting the very high number of endemic species often occurring on one single island.

\section{Topological roles}

The roles assigned to insular units by the topological analysis (Fig. 7) reflect their structural and biogeographical characteristics. Our results appear to corroborate several interesting patterns in topological roles. In particular, as already demonstrated by Carstensen et al. (2012, 2013) and Kougioumoutzis et al. (2014), the ultra-peripherals and peripherals can be seen as biodiversity sinks: islands within this category tend to be small and low, presenting less habitat diversity. Connectors can be seen as local stepping stones for the species dispersal, and the Salvages Islands are connectors for many spermatophytes in common between Madeiran and Canarian archipelagos. Similarly, Desertas and Porto Santo appear to be connectors for bryophytes between Madeira and Cape Verde modules. However, this likely is because all of the bryophytes recorded on Desertas and Porto Santo are also found on the Canary Islands, yet their presence is masked by the far greater number of bryophyte species recorded there than in the modules of Madeira and Cape Verde. On the other hand, El Hierro and Porto Santo are likely true connectors for birds, their eccentric position from the central module creates a distributional gradient very coherent with the biogeographic settlement of bird species.

The network hub islands represent the regional centers of speciation and dispersal (Carstensen et al. 2012) and in our analysis this is the role of: Tenerife, La Palma, Gran Canaria, El Hierro and Madeira (for fungi and lichens) and Lanzarote and Fuerteventura (for spermatophytes), this last result coinciding with Caujapé-Castells et al. (2017) syngameon approach. These are always large islands, with a central position within their modules and of remarkable biogeographic importance, as already pointed out by many authors (Fernández-Palacios 2011, Caujapé-Castells et al. 2017, Price et al. 2018). It should be noted that all major islands in the Canaries are very close to the role of network hub for spermatophytes, but the high number of multiple island endemics (MIEs) makes them standing out, instead, as module hubs.

More complex is the relationship between the traits of a species and its assignment to a particular biogeographic role. In general (Supplementary material Appendix 2), species typical of dense forests and mature habitats are categorized predominantly as peripherals, while coastal species and those living in open areas mainly play the role of connectors and network hubs.

Also species with a wide altitudinal range and/or ecological behaviour are usually placed among the network hubs, while species with lesser ecological amplitude are framed as peripheral. The dispersal strategies are also very influential, as shown by the increase in $l$ and $r$-values as the species distribution range increases. Groups of taxa well known for their effective long-distance dispersibility (such as birds, fungi, bryophytes, pteridophytes and lichens) showed smaller percentages of peripherals and ultra-peripherals. In all TOUs analysed, highly localized endemic species almost always assumed the role of ultra-peripheral, providing clear evidence of the relationship between the biogeographic role of a species and its ecological specialization. Although endemic species have not been especially distinguished in the processed matrices, their importance in determining the island roles and the topological properties of the network is implicitly significant. The processing of only the endemic contingent could have added additional information to network analysis, but would have provided less evidence of the inter-archipelagos connections.

\section{Limitations of the approach}

The taxonomic effort applied to species descriptions is likely uneven across the archipelagos. Cumulative number of arthropod taxa described does vary for the Canaries and Azores (Graham et al. 2017). Therefore, the current analysis is likely affected by the uneven accumulation of species descriptions for most taxonomic groups of each region. Consequently, the consistency of the TOUs among archipelagos will be affected by this disparity of data, as well as by possible inaccuracies due to human errors. In particular, in certain TOUs on Cape Verde - such as fungi, lichens and arthropods - the lack of knowledge is very obvious. The scarcity of species recorded in this archipelago may be not only due to the paucity of studies conducted and the discontinuous presence of researchers on Cape Verde but to the harsher environment. In the Azores, the relative scarcity of plant species may be due to an abundance of cryptic species, not yet recognized as such (Carine and Schaefer 2010, Schaefer et al. 2011). Despite unevenness in species records, analysis of the available data provided some interesting clues to the biogeographical and ecological understanding of Macaronesia.

Some dissimilarities can be due to methodological limits, as simulated annealing is recommended for node-rich networks (Carstensen and Olesen 2009), while for some TOUs (such as mammals) nodes were very few.

It is important to stress that our results are based on exotic species-free lists. In fact, as shown by Fernández-Lugo et al. (unpubl.), non-native species can increase the modular homogenization at the regional scale. Human pressure is a crucial driver of change in insular biogeographic pattern detection, and accounting for non-native and/or extinct species could produce very different and conflicting results (Sax and Gaines 2008).

\section{Conclusions}

Simulated annealing has been confirmed to be a useful tool to provide an objective classification of species into 
distributional categories and to correlate the island properties with their relative species richness. The information gathered in our study provides evidence that could be used for further analyses, such as the application of generalized dissimilarity models to quantify the influence of historical and environmental drivers in determining species distribution patterns within and among biogeographical units, both regionally and globally. The results obtained for some taxa suggest that the geographic distance and/or the macroclimatic conditions are less important than the size, age and orography of an island to determine the modularity of island groups.

Additionally, the roles assigned to the species can be correlated with a variety of traits related to the ecological requirements, dispersal capacity, distribution area, trophic level and others, which could allow obtaining objective results that could be used in studies on differential immigration and localization, as well as in actions to be taken to preserve natural areas.

In general, the results obtained were particularly significant in the analysis of species-rich TOUs and the observed patterns are strongly influenced by the taxa examined and by their long distance dispersal capabilities.

\section{References}

Arechavaleta, M. et al. (eds) 2005. Lista preliminar de especies silvestres de Cape Verde. (hongos, plantas y animales terrestres). - Consejería de Medio Ambiente y Ordenación Territorial, Gobierno de Canarias.

Arechavaleta, M. et al. (eds) 2010. Lista de especies silvestres de Canarias. Hongos, plantas y animales terrestres. - Gobierno de Canarias.

Beyhl, F. E. et al. 1995. Macaronesia. A biogeographical puzzle. - Bol. Mus. Mun. Funchal 4: 107-113.

Borges, P. A. V. et al. (eds) 2008. A list of the terrestrial fungi, flora and fauna of Madeira and Selvagens archipelagos. - Direcção Regional do Ambiente da Madeira and Univ. dos Açores, Funchal and Angra do Heroísmo.

Borges, P. A. V. et al. (eds) 2010. A list of the terrestrial and marine biota from the Azores. - Princípia, Cascais.

Carine, M. A. and Schaefer, H. 2010. The Azores diversity enigma: why are there so few Azorean endemic flowering plants and why are they so widespread? - J. Biogeogr. 37: 77-89.

Carstensen, D. W. and Olesen, J. M. 2009. Wallacea and its nectarivorous birds: nestedness and modules. - J. Biogeogr. 36: 1540-1550.

Carstensen, D. W. et al. 2012. Biogeographical modules and island roles: a comparison of Wallacea and the West Indies. - J. Biogeogr. 39: 739-749.

Carstensen, D. W. et al. 2013. The functional biogeography of species: biogeographical species roles of birds in Wallacea and the West Indies. - Ecography 36: 1097-1105.

Caujapé-Castells, J. 2011. Jesters, red queens, boomerangs and suffers: a molecular outlook on the diversity of the Canarian endemic flora. - In: Bramwell, D. and Caujapé-Castells, J. (eds), The biology of island floras. Cambridge Univ. Press, pp. 284-324.
Caujapé-Castells, J. et al. 2017. Island ontogenies, syngameons, and the origins and evolution of genetic diversity in the Canarian endemic flora. - Perspect. Plant Ecol. Evol. Syst. 27: 9-22.

de Nascimento, L. et al. 2009. The long-term ecology of the lost forests of la Laguna, Tenerife (Canary Islands). - J. Biogeogr. 36: 499-514.

de Nicolás, J. P. et al. 1989. Inter-island floristic similarities in the Macaronesian region. - Vegetatio 84: 117-125.

dos Santos, D. A. et al. 2008. Sympatry inference and network analysis in biogeography. - Syst. Biol. 57: 432-448.

Engler, A. 1879. Versuch einer Eintwicklungsgeschichte, insbesondere der Florengebiete seit der Tertiärperiode. I. Die extra-tropischen Gebiete der nördlischen Hemisphäre. - W. Engelmann.

Fattorini, S. 2009. On the general dynamic model of oceanic island biogeography. - J. Biogeogr. 36: 1100-1110.

Fattorini, S. 2010. The influence of geographical and ecological factors on island beta diversity patterns. - J. Biogeogr. 37: 1061-1070.

Fattorini, S. 2011. Influence of island geography, age and landscape on species composition in different animal groups. - J. Biogeogr. 38: 1318-1329.

Fernández-Palacios, J. M. 2011. The islands of Macaronesia. - In: Serrano, A. R. M. et al. (eds), Terrestrial arthropods of Macaronesia. Biodiversity, ecology and evolution. Sociedade Portuguesa de Entomología, pp. 1-30.

Fernández-Palacios, J. M. et al. 2011. A reconstruction of PalaeoMacaronesia, with particular reference to the long-term biogeography of the Atlantic island laurel forests. - J. Biogeogr. 38: 226-246.

Fernández-Palacios, J. M. et al. 2013. The importance of windows of opportunity for long-distance dispersal to or from oceanic islands: examples from the Macaronesian archipelagos. - In: Caujapé-Castells, J. et al. (eds), Proceedings of the AMURGA International Conferences on Island Biodiversity. Fundación Canaria Amurga-Maspalomas, pp. 16-22.

Fernández-Palacios, J. M. et al. 2016. Towards a glacial-sensitive model of island biogeography. - Global Ecol. Biogeogr. 25: 817-830.

Fernández-Palacios, J. M. et al. 2018. Terrestrial biota checklist of the Chinijo archipelago and Lobos (Canary Islands). - Sci. Insularum, in press.

Geldmacher, J. et al. 2000. The 40Ar/39Ar age dating of the Madeira and hotspot track (eastern North Atlantic). - Geochem. Geophys. Geosyst. 1: 1-26.

Graham, N. R. et al. 2017. Island ecology and evolution: challenges in the Anthropocene. - Environ. Conserv. 44: 323-325.

Guimerà, R. and Amaral, L. A. N. 2005a. Cartography of complex networks: modules and universal roles. - J. Stat. Mech. 2: 1-13.

Guimerà, R. and Amaral, L. A. N. 2005b. Functional cartography of complex metabolic networks. - Nature 433: 895-900.

Guimerà, R. et al. 2004. Modularity from fluctuations in random graphs and complex networks. - Phys. Rev. E 70: 1-4.

Guimerà, R. et al. 2007. Classes of complex networks defined by role-to-role connectivity profiles. - Nat. Phys. 3: 63-69.

Heaney, L. R. 2000. Dynamic disequilibrium: a long-term, largescale perspective on the equilibrium model of island biogeography. - Global Ecol. Biogeogr. 9: 59-74.

Kougioumoutzis, K. et al. 2014. Network biogeographical analysis of the central Aegean archipelago. - J. Biogeogr. 41: 1848-1858.

Kunkel, G. 1980. Die Kanarischen Inseln und ihre Pflanzenwelt. - Gustav Fischer Verlag. 
Lobin, W. 1982. Untersuchung über Flora, Vegetation una biogeographische Beziehungen der Kapverdischen Archipel. - Cour. Forsch. Inst. Senckenberg 53: 1-112.

Lomolino, M. V. 2000. A call for a new paradigm of island biogeography. - Global Ecol. Biogeogr. 9: 1-6.

Lüpnitz, D. 1995. Kanarischen Inseln. Florenvielfalt auf engen Raum. - Palmengarten Sonderh. 23: 1-117.

MacArthur, R. and Wilson, E. O. 1967. The theory of island biogeography. - Princeton Univ. Press.

Martín González, E. 2009. El legado paleontológico de nuestras islas: un patrimonio a conservar. - In: Afonso-Carrillo, J. (ed.), Misterios de la Gea: descifrando los enigmas ocultos en rocas, gases, agua y fuego. Actas IV Semana Científica Telesforo Bravo. Inst. de Estudios Hispánicos de Canarias, pp. 99-124.

Olesen, J. M. et al. 2007. The modularity of pollination networks. - Proc. Natl Acad. Sci. USA 104: 19891-19896.

Podani, J. and Schmera, D. 2011. A new conceptual and methodological framework for exploring and explaining pattern in presence-absence data. - Oikos 120: 1625-1638.

Price, J. P. et al. 2018 Colonisation and cladogenesis shape species-area relationships in three Macaronesian archipelagos. - J. Biogeogr. doi:10.1111/jbi.13396

Rijsdijk, K. F. et al. 2014. Quantifying surface-area changes of volcanic islands driven by Pleistocene sea-level cycles: biogeographical implications for the Macaronesian archipelagos. - J. Biogeogr. 41: 1242-1254.

Supplementary material (Appendix ECOG-03909 at <www. ecography.org/appendix/ecog-03909>). Appendix 1-3.
Santos-Guerra, A. 1999. Apuntes a la Biogeografía de las islas Cabo Verde. - Rev. Acad. Canar. Cienc. 11: 201-211.

Sax, D. and Gaines, S. D. 2008. Species invasion and extinction. The future of native biodiversity in islands. - Proc. Natl Acad. Sci. USA 105: 11490-11497.

Schaefer, H. et al. 2011. The Linnean shortfall in oceanic island biogeography: a case study in the Azores. - J. Biogeogr. 38: 1345-1355.

Torre, G. et al. 2018. Data from: Network analysis by simulated annealing of taxa and islands of Macaronesia (North Atlantic Ocean). - Dryad Digital Repository, <https://doi.org/10.5061/ dryad.v190524>.

Traveset, A. et al. 2013. Invaders of pollination networks in the Galápagos Islands: emergence of novel communities. - Proc. Biol. Sci. 280: 20123040.

Trøjelsgaard, K. et al. 2013. Island biogeography of mutualistic interaction networks. - J. Biogeogr. 40: 2020-2031.

Vanderpoorten, A. et al. 2007. Does Macaronesia exist? Conflicting signal in the bryophyte and pteridophyte floras. - Am. J. Bot. 94: 625-639.

Warren, B. H. et al. 2015. Islands as model systems in ecology and evolution: prospects fifty years after MacArthur-Wilson. - Ecol. Lett. 18: 200-217.

Whittaker, R. J. et al. 2008. A general dynamic theory of oceanic island biogeography. - J. Biogeogr. 35: 977-994.

Whittaker, R. J. et al. 2017. Island biogeography: taking the long view of nature's laboratories. - Science 357: eaam8326. 